\title{
A study on the impacts of Smartphone addiction
}

\author{
Napassphol Sinsomsack \& Waiphot Kulachai \\ Burapha University, Chonburi, Thailand
}

\begin{abstract}
The objective of this study was to examine Smartphone addiction among high school students and its impacts. The samples of the study were 341 high school students in the Eastern region of Thailand derived from stratified random sampling. The questionnaire was used to collect the data. The data were then analyzed using correlation statistics. The results indicated that Smartphone addiction had a positive impact on mood disorders. It also caused a negative impact on health, family relationship, social relationship, and academic performance of the high school students.
\end{abstract}

Keywords: Smartphone addiction, disorders.

\section{INTRODUCTION}

Communication has played an important role in our society since a long time ago. Its tools and equipment have been developed over times which enhance us to communicate with others easier and faster. Recently, a Smartphone has become the most important communication tool in people' daily lives (Suparp 2006).

Smartphone has been developed since the emerging of the first mobile phone dating back to 1983 . During 1993-2003, digital technology was applied to Smartphone technology creating various features. When the Smartphone could connect to the internet, it could provide various features such as camera, games, and a number of applications. Most importantly, the price of the Smartphone has been declining dramatically. These lead to the popularity of the Smartphone in recent days (Palachaipiromsil 2011). People can use Smartphone to communicate online with friends so they can conquer live their lives more conveniently not just only for communication, but also for their works, and personal entertainment (Boonuyang et al. 2015).

In Thailand, the number of Smartphone users had increased by $81.4 \%$ during $2012-2016$. It is reported that there were 51 million Smartphone users in Thai- land according to the report of the National Statistical Office (2016). However, a Smartphone also causes negative impacts on people lives since many of them pay much attention to playing games, chatting with friends, surfing the internet, listening to music, and watching movies. They keep doing these activities day by day and finally addict to using a Smartphone (Jitsukpluem 2014).

Smartphone addiction leads to various consequences. It could have an impact on people mood and temper. Previous studies (Ravichandran 2009, Hyun-Seok et al. 2012, Sarwar 2013, Petchkhum 2014, Arbi et al. 2014, Mok et al. 2014, Park, \& Lee 2014, Park \& Park 2014, Park et al. 2014, Derakhshani \& Shirazi 2015, Park et al. 2015, Thongjuephong 2016) indicated that Smartphone addiction had a positive impact on mood disorder. Hence, we proposed the hypothesis as follows:

H1: Smartphone addiction has a positive impact on mood disorder

Arbi et al. (2014) stated that Smartphone addiction resulted in negative impact on exercising, eating, and sleeping as well as caused health problems. In addition, Smartphone addiction could lead to mental disorder (Jones 2014, Mok et al. 2014). Various studies also founded the negative impacts of Smartphone on health of addicted people (Ravichan- 
dran 2009, Sawar 2013, Petchkhum 2014, Park \& Park 2014, Park et al. 2014, Abu-Shanab \& Haddad 2015, Park et al. 2015, Thongjuephong 2016). Hence, the second hypothesis was proposed as follows:

H2: Smartphone addiction has a negative impact on health

Besides negative impacts as discussed in the previous section, Smartphone addiction also has negative consequences on a family relationship of young people who addict to the Smartphone. The study by Ravichandran (2009) reported that Smartphone addiction led to a poor relationship among family members. This was in line with other previous studies (Baron 2010, Sarwar 2013, Petchkhum 2014, Jones 2014, Park et al. 2014, Abu-Shanab \& Haddad 2015, Derakhsha \& Shirazi 2015). The studies by Jeong \& Lee (2015) provided supportive findings. Hence, the third hypothesis was proposed as follows:

H3: Smartphone addiction has a negative impact on family relationship

Some researchers examined the impact of Smartphone addiction on academic performance of young people, especially high school students (Hyun-Seok et al. 2012, Sarwar 2013, Mok et al. 2014, Park \& Park 2014, Park et al. 2014, AbuShanab \& Haddad 2015, Al-Barashdi et al. 2015, Jeong \& Lee 2015 and Lee \& Cho 2015). Most of them found a negative impact of Smartphone addiction on students' academic performance. Hence, the fourth hypothesis was proposed as follows:

H4: Smartphone addiction has a negative impact on students' academic performance

The research conducted by Baron (2010) provided interesting finding. The more likely the people addict to a Smartphone, the most likely they will experience poor social relationship. This result was supported by later studies (Hyun-Seok et al. 2012, Petchkhum 2014, Park \& Lee 2014, Derakhshani \& Shirazi 2015, Jeong \& Lee 2015, Thongjuephong 2016). Hence, the fifth hypothesis was proposed as follows:

H5: Smartphone addiction has a negative impact on social relationship

\section{METHODOLOGY}

\subsection{Participants}

The samples of the study were 341 high school students in the Eastern region of Thailand derived from stratified random sampling. Most of them were female accounting for $62.2 \%$. Approximately $44.9 \%$ were Grade 10 students. Most of them lived with their families (85\%). About $48 \%$ of the respondents reported having their first Smartphone when they were in the secondary school.

\subsection{Measures}

For all measures in the study, except demographic questions, respondents indicated their level of agreement with the items using a 5-point's Likert response scale anchored by (1) strongly disagree and (5) strongly agree. Each measure is illustrated as the followings;

Smartphone addiction measure consisted of 15 items developed by the authors. The measurement provided an alpha reliability of .86. The example items included "I always check message from friends on my Smartphone", "I prefer using my Smartphone rather than doing other activities", and "I always use my Smartphone before going to bed."

Mood disorder was measured using a 4-item questionnaire developed by the authors. The measurement provided an alpha reliability of .86 . The example items included "I always upset when I am prohibited using Smartphone" and "Whenever my Smartphone runs out of battery, I will be very anxious."

Health problem was measured by a 3-item questionnaire developed by the authors. The measurement provided an alpha reliability of .79. The example items included "I always have finger-pain after continuously using my Smartphone for hours", "I have less time for sleeping", and "I usually have a neck and shoulder pain after continuously using my Smartphone for hours."

Family relationship measure consisted of 5 items developed by the authors. The measurement provided an alpha reliability of .85 . The example items included "After back from school, I always use my Smartphone rather than do activities with my family members", "My family members have less communication with each other since they have their own Smartphone", and "After getting up in the morning, I always find my Smartphone rather than communicating with other family members."

Academic performance measure consisted of 4 items developed by the authors. The measurement provided an alpha reliability of .87 . The example items included "I use my Smartphone while studying", "I pay more attention to my Smartphone rather than prepare for the coming exam", and "I do not understand what my teacher says in the class."

Social relationship measure consisted of 5 items developed by the authors. The measurement provided an alpha reliability of .82. The example items included "I always use Smartphone even in the public places", "I prefer using my Smartphone rather than 
doing activities with friends", and "I always use my Smartphone while traveling by public transportation."

\subsection{Analysis}

Descriptive statistics such as mean, frequency, percentage, and standard deviation were employed to analyze and explain some attributes of the variables. In addition, correlation statistics was employed for hypothesis testing

\section{RESULTS}

The correlation analysis in this study showed whether and how strongly pairs of variables are related. The variables in this analysis consisted of smartphone addiction (SA), mood disorder (MD), health problem (HP), family relation (FR), academic performance (AP), and social relation (SR). Pearson's $r$ correlation was employed to measure the degree of the relationship between linearly related variables. The results of the study are illustrated in Table 1.

Table 1. Paerson's r correlation.

\begin{tabular}{lllllll}
\hline & SA & MD & HP & FR & AP & SR \\
\hline SA & - & & & & & \\
MD & $0.67^{* *}$ & - & & & & \\
HP & $0.48^{* *}$ & $0.49^{* *}$ & - & & & \\
FR & $0.62^{* *}$ & $0.60^{* *}$ & $0.55^{* *}$ & - & & \\
AP & $0.57^{* *}$ & $0.56^{* *}$ & $0.46^{* *}$ & $0.60^{* *}$ & - \\
SR & $0.63^{* *}$ & $0.57^{* *}$ & $0.52^{* *}$ & $0.69^{* *}$ & $0.64^{* *}$ & \\
\hline$* * \mathrm{p}<0.01$. & & & & & &
\end{tabular}

According to Table 1, Smartphone addiction has the highest relationship with mood disorder $(\mathrm{r}=.667)$ followed by social relationship $(\mathrm{r}=.625)$, family relationship ( $\mathrm{r}=.620)$, academic performance $(\mathrm{r}=.570)$, and health problem $(\mathrm{r}=.481)$ respectively. These indicate that Smartphone addiction has a high level of relationship with mood disorder, social relationship, and family relationship. However, it has a moderate relationship with academic performance and health problem. Table 2 shows the result of hypothesis testing.

Table 2. Hypothesis testing.

\begin{tabular}{lr}
\hline \multicolumn{1}{c}{ Hypothesis } & Result \\
\hline H1: smartphone addiction has a positive impact & Accepted \\
on mood disorder & \\
H2: smartphone addiction has a negative impact & Accepted \\
on health & \\
H3: smartphone addiction has a negative impact & Accepted \\
$\begin{array}{l}\text { on family relationship } \\
\text { H4: smartphone addiction has a negative impact }\end{array}$ & Accepted \\
$\begin{array}{l}\text { on students' academic performance } \\
\text { H5: smartphone addiction has a negative impact } \\
\text { on social relationship }\end{array}$ & Accepted \\
\hline
\end{tabular}

\section{DISCUSSION}

The finding indicates a strong positive relationship between Smartphone addiction and mood disorder. This means that the more likely the students addict to a Smartphone, the most likely they will have a high level of mood disorder. This finding supports and in line with previous studies (Ravichandran 2009, Hyun-Seok et al. 2012, Sarwar 2013, Petchkhum 2014, Arbi et al. 2014, Mok et al. 2014, Park \& Lee 2014, Park \& Park 2014, Park et al. 2014, Derakhshani \& Shirazi 2015, Park et al. 2015, Thongjuephong 2016). Addiction to Smartphone also leads to emotional fluctuation which finally results in depression.

As discussed in the previous section, Smartphone addiction could lead to a poor social relationship (Hyun-Seok et al. 2012, Petchkhum 2014, Park \& Lee 2014, Derakhshani \& Shirazi 2015, Jeong \& Lee 2015, Thongjuephong 2016). The finding of our study is in line with the previous researches on these issues. Students who are addicted to the Smartphone have poor social interaction since they might have no/little attachment to their families and schools and they are not involved in any activities. Hence, they spend most of their time with the Smartphone.

We found that Smartphone addiction affected the relationship in the family. Students who were addicted to Smartphone reported that they had a poor relationship with their families. They seldom communicate with other family members since they always pay attention to their Smartphone rather than place importance on doing activities with other members. The finding supports the results of previous studies (Baron 2010, Sarwar 2013, Petchkhum 2014, Jones 2014, Park et al. 2014, Abu-Shanab \& Haddad 2015, Derakhsha \& Shirazi 2015, Jeong \& Lee 2015).

The result of this study also pointed out that Smartphone addiction had negative consequences on students' academic performance. Many of them use their Smartphone while studying. They always pay less attention to the teachers. Hence, they cannot understand the lessons given by their teachers. This support the finding of previous studies (Hyun-Seok et al. 2012, Sarwar 2013, Mok et al. 2014, Park \& Park 2014, Park et al. 2014, Abu-Shanab \& Haddad 2015, Al-Barashdi et al. 2015, Jeong \& Lee 2015, Lee \& Cho 2015 and Sundari 2015).

Our research finding also supported that Smartphone addiction had negative impacts on students' health. Some of them experienced neck and finger pain since they had used their Smartphone playing games, chatting, and surfing internet for long hours. The finding is in line with the previous studies (Ravichandran 2009, Sarwar 2013, Pet- 
chkhum 2014, Park \& Park 2014, Park et al. 2014, Abu-Shanab \& Haddad 2015, Park et al. 2015, Thongjuephong 2016). Additionally, whenever students have a health problem, it may result in their poor academic performance.

\section{RECOMMENDATION}

We found that Smartphone addiction had negative impacts on a social relationship, family relationship, health problem, and poor academic performance of the students. In addition, it also caused mood fluctuation and mood disorder among high school students. These could lead to a social problem. Some parents use a Smartphone to keep their children silent without concerning about its impacts. Parents nowadays should be acknowledged about the negative consequences of the Smartphone so they can explain their children properly. They should be with their children more which will make them attaching, committing, and involving in family, school, and community. The most likely they are attached to the family, school, and social institution; the more likely they will be away from the Smartphone

Mass media should pay attention to this issue by providing information about the consequences of Smartphone usage through TV programs, radio, games, cartoons, movies, and TV series. Hence, students, parents, and people, in general, would be concerned more on this problem.

This study focused on students in the Eastern region of Thailand. However, the sample size is quite small. Future studies should be conducted in other areas of Thailand. Comparative studies among different parts of the country should also be important to pile up the body of knowledge on this topic. Different kinds of research should be employed to get more in-depth finding. In addition, other consequences of Smartphone addiction should be also examined.

\section{CONCLUSION}

We are nowadays living in the globalization era. Internet-based technology has been developed and changed dramatically. A Smartphone is one of the most important technologies enhancing people to connect and communicate easier and faster. However, it also has various drawbacks. It causes a health problem, poor family relationship, poor social interaction, and poor academic performance. It also leads to mood disorder among high school students. To deal with this problem, parents and young people should be acknowledged about the consequences of using Smartphone through various media channels. Most importantly, the parents themselves should pay more attention to their children by giving them more time and affection.

\section{REFERENCES}

Abu-Shanab, E. \& Haddad, E. 2015. The influence of smartphones on human health and behavior: Jordanians' perceptions. International Journal of Computer Networks and Applications 2(2): 52-56.

Al-Barashdi, H., Bouazza, A., \& Jabur, N. 2015. Smartphone addiction among university undergraduates: A literature review. Department of Information Studies: Sultan Qboos University.

Baron, N. S. 2010. The dark side of mobile phones. Department of Language and Foreign Studies, American University, Washington DC, USA.

Derakhshani, N. \& Shirazi, M. 2015. The role of smartphone addiction in emotional regulation of boys' high school students in chabahar city. Indian journal of fundamental and applied life science 5(3): 1105-1108.

Hyun-Seok, C., Hyun-Kyung, L., \& Jeong-Cheol, H. 2012. The influence of smartphone addiction on mental health, campus life and personal relations-Focusing on $\mathrm{K}$ university students. Journal of the Korean Data \& Information Science Society 23(5): 1005-1015.

Jeong, H. \& Lee, Y. 2015. Smartphone addiction and empathy among nursing students. Advanced science and Technology Letters 88(47): 224-228.

Jitsukpluem, W. 2014. Lack of sociability. Unpublished master thesis. Thailad: Silpakorn University.

Jones, T. 2014. Students' cell phone addiction and their opinions. The Elon Journal of Undergraduate Research in Communications 5(1): 74-80.

Lee, J. \& Cho, B. 2015. Effects of self-control and school adjustment on smartphone addiction among elementary school students. Seoul-Korea: Educational technology, College of education Ewha Womans University.

Mok, J.Y., Choi S., Kim, D., Choi, J., Lee, J.A., \& Choi, E.S.W. 2014. Latent class analysis on internet and smartphone addiction in college students. Neuropsychiatric Disease and Treatment 10: 817-828.

Park, N. \& Lee, H. 2014. Nature of youth smartphone addiction in Korea. Media Information Research of Seoul National University 51(1): 100-132.

Park, C. \& Park, Y. 2013. The conceptual model on smart phone addiction among early childhood. International Journal of Social Science and Humanity 4(2): 147-150.

Park, C.J., Hyun, J.S., Kim, J.Y., \& Lee, K.E.. 2014. Impact of personal time-related factor on smartphone addiction of female high school students. Proceedings of the World Congress on Engineering and computer science.

Park, J., Kim, J., Kim, J., Kim, K., Kim, N., Choi, I., Lee, S., \& Yim, J. 2015. The effects of heavy smartphone use on the cervical angle, pain threshold of neck muscles and depression. Advanced Science and Technology Letters 91(3): 1217.

Petchkhum, P. 2014. Smartphone usage behaviors among Thai teenagers and its negative impacts on themselves and societies. Unpublished master thesis. Thailand: Sripathum University.

Ravichandran, S.V. 2009. Mobile phones and teenagers: Impact, Consequences and concerns parents/ caregivers per- 
spectives. Unpublished master thesis, Unitec Institute of Technology.

Sawar, M. 2013. Impact of smartphone's on society. European Journal of Scientific Research 98(2): 216-226.

Suparp, S. 2006. Revolution of communication and technology. Newsletter Science 3(1): 18-20.

Thongjuephong, P. 2016. Factors and effects of smart phone addiction to job performance, nomo-phobia and conflict with others. Journal of Information System in Business 2(3): 40-54. 